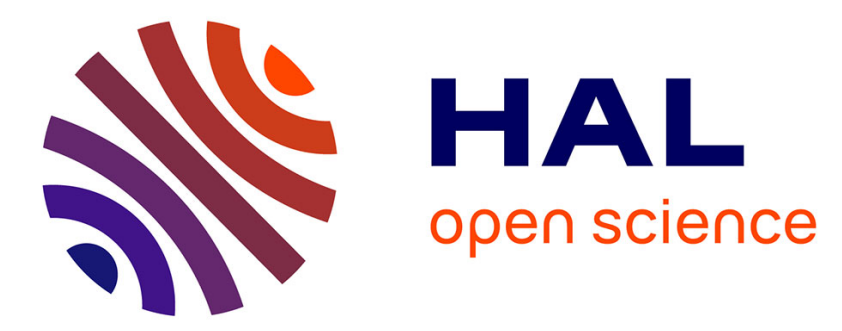

\title{
Heterogeneity and the trade-off between ecological and productive functions of agro-landscapes: a model of cattle-bird interactions in a grassland agroecosystem
} Rodolphe Sabatier, Luc Doyen, Muriel Tichit

\section{- To cite this version:}

Rodolphe Sabatier, Luc Doyen, Muriel Tichit. Heterogeneity and the trade-off between ecological and productive functions of agro-landscapes: a model of cattle-bird interactions in a grassland agroecosystem. Agricultural Systems, 2014, 126, pp.38-49. 10.1016/j.agsy.2013.02.008 . hal-01198013

\section{HAL Id: hal-01198013 \\ https://hal.science/hal-01198013}

Submitted on 27 May 2020

HAL is a multi-disciplinary open access archive for the deposit and dissemination of scientific research documents, whether they are published or not. The documents may come from teaching and research institutions in France or abroad, or from public or private research centers.
L'archive ouverte pluridisciplinaire HAL, est destinée au dépôt et à la diffusion de documents scientifiques de niveau recherche, publiés ou non, émanant des établissements d'enseignement et de recherche français ou étrangers, des laboratoires publics ou privés. 


\title{
Heterogeneity and the trade-off between ecological and productive functions of agro-landscapes: A model of cattle-bird interactions in a grassland agroecosystem
}

\author{
Rodolphe Sabatier ${ }^{\mathrm{a}, \mathrm{b}, *}$, Luc Doyen ${ }^{\mathrm{c}}$, Muriel Tichit ${ }^{\mathrm{a}, \mathrm{b}}$ \\ a INRA, UMR 1048 SADAPT, F-75005 Paris, France \\ ${ }^{\mathrm{b}}$ AgroParisTech, UMR 1048 SADAPT, F-75005 Paris, France \\ ${ }^{\mathrm{c}}$ CNRS, UMR 7204 CERSP, MNHN, F-75005 Paris, France
}

\section{A R T I C L E I N F O}

\section{Article history:}

Available online $\mathrm{xxxx}$

\section{Keywords:}

Landscape

Grassland

Grassland birds

Lapwing

Model

\begin{abstract}
A B S T R A C T
There is empirical evidence that the proportions of different land uses or management regimes and their spatial arrangements can affect the long-term dynamics of bird species in agro-landscapes. The aim of our study was to assess the extent to which biodiversity can be enhanced by altering landscape structure without reducing agricultural production. We focused on a wader bird, the Northern Lapwing (Vanellus vanellus), in grassland landscapes in the Marais Poitevin area (France). For the purposes of our study, we developed a spatially explicit, dynamic model linking grass dynamics in grazed and mowed fields to lapwing population dynamics on a landscape scale. We then computed contrasting landscapes composed of fields with different management regimes that compensated for or complemented each other. The mechanism of compensation corresponded to the case where one management regime is favorable to a species, and the other is less so. The mechanism of complementation corresponded to the case where each of two management regimes is partially favorable to a species. Our results showed that the relative share of different management regimes was the main driver of Northern Lapwing dynamics in landscapes characterized by compensatory management regimes. In landscapes characterized by complementary management regimes, the spatial arrangement of the management regimes was also an important, albeit secondary, driver of bird population dynamics. Managing the spatial arrangement of management regimes is a way to improve the trade-off between ecological and agricultural performances on a landscape scale by improving ecological performances without altering the level of production. Landscape heterogeneity appears to be a promising way to reconcile the agricultural and ecological functions of agriculture, although it raises several issues concerning collective management.
\end{abstract}

(ㄷ) 2013 Elsevier Ltd. All rights reserved.

\section{Introduction}

Agricultural intensification in Europe has resulted in a substantial decline in biodiversity, with farmland bird specialists being particularly at risk (Julliard et al., 2003; Donald et al., 2006). It has entailed changes in farming practices such as increased mechanization and the broad use of chemical inputs on a field scale, as well as landscape-scale changes such as field enlargement, the standardization of practices, and the loss of semi-natural elements. This homogenization of agro-landscapes has reduced the availability and diversity of resources (e.g., food and shelter) and is one of the main drivers of biodiversity loss (Tscharntke et al., 2005).

Recent reviews highlight the importance of heterogeneity in reversing the decline of biodiversity in agricultural landscapes

\footnotetext{
* Corresponding author at: AgroParisTech, UMR 1048 SADAPT, F-75005 Paris, France.

E-mail address: rodolphe.sabatier@agroparistech.fr (R. Sabatier).
}

(Benton et al., 2003; Tscharntke et al., 2005). Heterogeneity is a complex notion and has been defined in different ways (Sparrow, 1999). The term synthesizes two landscape characteristics: first, the proportions of different agricultural land uses or management regimes; and second, their spatial arrangement (i.e., the composition and structure of the landscape) (Burel and Baudry, 1999). Benton et al. (2003) and Tscharntke et al. (2005) point out the importance of landscape heterogeneity and complexity to hosting a diversity of species but provide few details on the underlying mechanisms. More recently, Fahrig et al. (2011) went further by describing the different aspects of the functional dimension of heterogeneity. This functional dimension of heterogeneity is very much in line with former theoretical and empirical studies that analyzed the interactions between habitats and proposed various hypotheses linking landscape composition to biodiversity (Dunning et al., 1992; Andren et al., 1997). They distinguish two types of mechanisms (compensation and complementation), depending on the nature of the various habitats generated by each 
management regime and on the way they interact on the ecological point of view. These two types of mechanisms have been synthesized by Brotons et al. (2005). The mechanism of compensation corresponds to the situation where one land-use type is favorable to a given species and a second is of lower quality (Andren et al., 1997). The mechanism of complementation corresponds to the case where each of the two management regimes is partially favorable to a species, and both management regimes are required for the species to complete its life cycle; e.g., one habitat provides shelter, while another provides forage (Dunning et al., 1992). The proportion of the different management regimes is then a strong driver of the mechanism of complementation. However, it is also likely that the spatial arrangement of the landscape interacts with the mechanism of complementation and modifies its outcome.

Many studies and policies focussing on the ecological functions of agro-landscapes implicitly posit that a favorable habitat (e.g., a field under an agri-environment scheme) compensates for the effects of an unfavorable one (e.g., a field with conventional management). This approach is embodied in the model of Green et al. (2005) contrasting intensive land use, which is detrimental to biodiversity, to extensive land use, which is favorable to biodiversity. The compensatory view also prevailed for a long time in conservation policies for agro-ecosystems. For example, Swiss agricultural policy imposes a minimum threshold of $7 \%$ compensatory areas in agricultural landscapes (Albrecht et al., 2007). But along with the composition of landscapes, landscape structure is increasingly considered a major driver of biodiversity, and the heterogeneity of landscapes is starting to be taken into account in conservation policies. These include introducing measures of the mosaic management of habitats in the Netherlands (Melman et al., 2010) to protect the Black-Tailed Godwit (Limosa limosa).

The proportion of different management regimes in the total cultivated area of a farm is an important driver of ecological performance (Jouven and Baumont, 2008; Tichit et al., 2011). However, converting some intensively managed fields into extensive ones often involves a trade-off in production (Sabatier, 2010). In this context, acting on the spatial arrangement of management regimes to increase the heterogeneity of landscapes without altering the proportions of different management regimes could be an important lever for reconciling productive and ecological functions of agrolandscapes, because it promotes mechanisms of complementation.

The objective of this study was to assess the extent to which biodiversity can be enhanced by altering landscape structure without reducing agricultural production. The following two hypotheses were successively tested:

1. In a landscape composed of complementary management regimes, the spatial structure of the landscape influences the ecological performance (Fig. 1a).

2. Increasing the complexity of the landscape structure makes it possible to offset the trade-off between agricultural and ecological performances (Fig. 1b).

Testing such hypotheses in the field would mean monitoring several landscapes with different land-use proportions and different spatial structures (all other things being equal) and recording data on ecological and agricultural performances. A simple way to have a first overview is to use a modeling approach. In this study, we developed a model that formalizes the interactions between agricultural management regimes and the dynamics of a bird population (Northern Lapwing) in a landscape consisting of permanent grasslands. Our aim was to build a theoretical model, still as realistic as possible, to reveal through simulations how the spatial arrangements of management regimes can impact a target species. The model simulates how Lapwing populations are affected by the proportions of different management regimes and the complexity of the spatial arrangement. Each landscape is characterized by its performances: ecological (population size at time horizon) and agricultural (average grazed-grassland production). We successively simulated series of landscapes composed of two complementary management regimes, two compensatory management regimes, or three management regimes leading to both complementary and compensatory mechanisms.

\section{Material and methods}

\subsection{Description of the case study}

The case study was focussed on the population dynamics of the Northern Lapwing (Vanellus vanellus) in a wet-grassland landscape on the French Atlantic coast (Marais Poitevin, $46^{\circ} 22^{\prime} \mathrm{N}, 1^{\circ} 25^{\prime} \mathrm{W}$ ). These grasslands are anthropomorphic agro-ecosystems. Whereas, on the one hand, their maintenance depends on livestock farming, on the other hand, over-intensive management of grasslands is detrimental to biodiversity (Durant et al., 2008b; Vickery et al., 2001; Sabatier et al., 2010). Waders reproduce in grasslands, and their life cycle is closely linked to the management practices and characteristics of landscapes (reviewed in Durant et al., 2008b). A large part of their life cycle depends on the direct and indirect effects of management practices on the field scale (Sabatier et al., 2010). The direct effect of management occurs before hatching, when eggs are exposed to trampling by cattle (Beintema and Muskens, 1987). Indirect effects linked to habitat quality, such as predation risks or food availability, occur after hatching, as juveniles leave the nest in their first month of life and disperse to a neighboring area, where they remain quite sedentary (Redfern, 1982; Johansson and Blomqvist, 1996; Kruk et al., 1997). Since they collect food by themselves and do not depend on their parents for foraging, they are highly sensitive to habitat quality at this time in the life cycle. This habitat quality depends on grass height and structure (review in Durant et al., 2008b). Therefore, their dispersal through fields of different grass heights just after hatching is an important mechanism in their population dynamics in addition to the direct and indirect effects on a field scale. After the first month, juveniles strongly increase their mobility by starting to fly. Due to this dispersal behavior, waders are good model species for a multi-scale analysis of interactions between agricultural management regimes and ecological dynamics. Of the different wader species nesting in our study area, the Northern Lapwing (hereafter simply referred to as the Lapwing) was by far the most common and best studied. We therefore focussed our study on this species.

\subsection{Model overview}

We developed a spatially explicit model that represents a grassland landscape, consisting of fields with different grasslandmanagement practices, exploited for beef-cattle farming. This agro-ecosystem is seen both as a feeding resource for cattle and as the habitat of the Lapwing. The landscape is composed of $K=64$ fields represented in a lattice grid of 64 square pixels of 4 ha. Given the high geometric regularity of the real landscape shaped by rills and canals, this lattice grid can be considered to be a reasonable approximation. The dynamics are discrete in time with a time step of 1 month and a time horizon of 2 years ( $T=24$ months). The model links the dynamics of the grass biomass of a set of fields to the dynamics of a population of Lapwings (Fig. 2). Both dynamics are adapted from Tichit et al. (2007) and Sabatier et al. (2010). The grassland sub-model simulates grass growth controlled by grazing or mowing in each field. The Lapwing sub-model simulates the dynamics of a Lapwing population in relation to the direct and indirect effects of grazing and mowing 


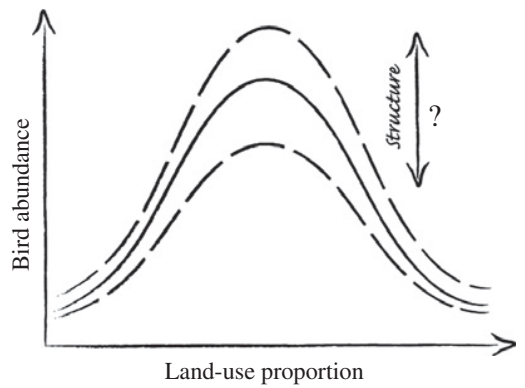

(a) Hypothesis 1

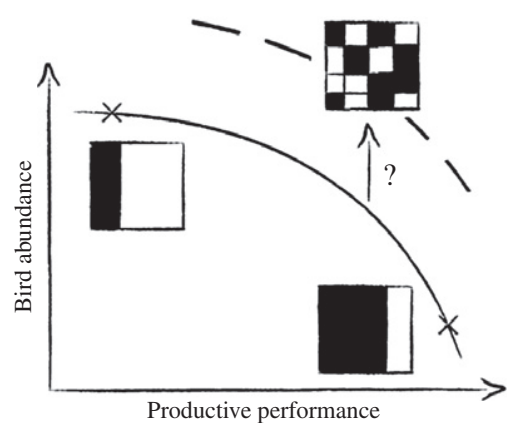

(b) Hypothesis 2

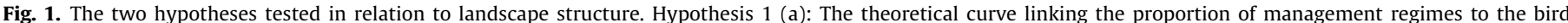

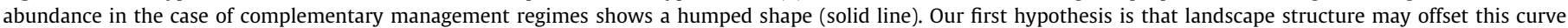

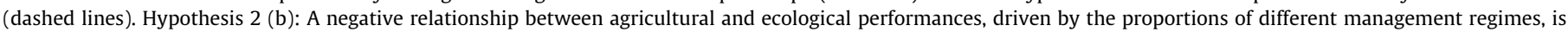

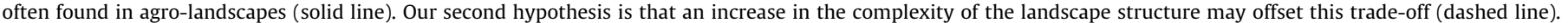

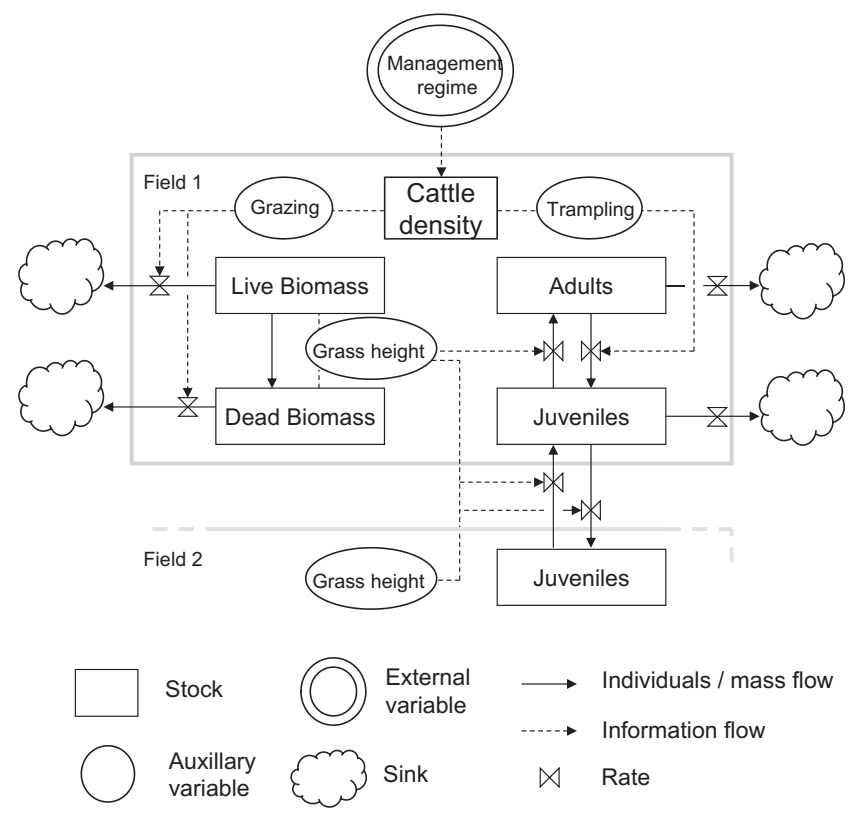

Fig. 2. Forrester diagram of the model, focused on one field and one neighboring field. Lapwing population is controlled by cattle directly through nest trampling and indirectly through grazing; juvenile re-distribution depend on grass height.

on Lapwing demographic parameters. In grazed fields, grazing may have a direct negative effect on the Lapwing's fecundity (i.e. the number of hatched eggs) due to the destruction of nests through trampling by cattle, when the grazing period coincides with the nesting stage. Grazing also modifies the grass height that determines habitat quality [e.g., feeding resources (Whittingham et al., 2000) and predation (Isaksson, 2009)] for juveniles. In our model, this indirect effect is reflected by declining juvenile survival with increasing grass height. Lapwings nest quite early in the year, and mowing occurs after the critical stage of their life cycle (end of May). Therefore, in mowed fields, only grass height impacts on the juveniles' survival. Along with the direct and indirect effects of management, the Lapwing sub-model also includes the juveniles' re-distribution from one adjacent field to another in the month following hatching.

A detailed list of parameters is given in Table 1.

\subsection{Dynamics of grazed or mowed grasslands}

The grassland dynamics are formalized through a matrix model adapted from Hutchings and Gordon (2001) reflecting growth,
Table 1

List of parameters.

\begin{tabular}{ll}
$B_{L, k}$ & Live biomass $\left(\mathrm{g} \mathrm{m}^{-2}\right)$ \\
$B_{D, k}$ & Dead biomass $\left(\mathrm{g} \mathrm{m}^{-2}\right)$ \\
$h$ & Grass height $(\mathrm{cm})$ \\
$u_{1, k}$ & Cattle density $\left(\mathrm{LU} \mathrm{ha}^{-1}\right)$ \\
$u_{2, k}$ & Mowing event \\
$t$ & Time (months) \\
$T$ & Time horizon (months) \\
$N_{j u v, k}$ & Juvenile population \\
$N_{a d, k}$ & Adult population \\
$\alpha$ & Proportion of females at reproductive age \\
$\sigma$ & Sex ratio \\
$f^{\max }$ & Maximum fecundity \\
$\eta$ & Daily survival rate of the eggs \\
$t^{*}$ & Length of the incubation period of the eggs (days) \\
$c$ & Intra specific competition rate \\
$q$ & Grazing parameter $\left(\mathrm{g} \mathrm{LU}^{-1}\right)$ \\
\hline
\end{tabular}

senescence, and the decay of live- and dead-grass biomass. Grass biomass at time $t+1$ depends on grass biomass at time $t$ and on management practices. In each field $k$, the grass biomass $B_{k}(t)$ is represented in the form of a vector $\left[\begin{array}{c}B_{L, k} \\ B_{D, k}\end{array}\right]$ (live biomass, dead biomass) expressed in $g$ organic matter per $\mathrm{m}^{2}$. Grass height is related to grass biomass by a linear function $h\left(B_{k}(t)\right)$. Biomass dynamics are controlled by cattle density at grazing $u_{1, k}(t)$ and by mowing $u_{2, k}(t)$ :

$B_{k}(t+1)=A\left(t, B_{k}(t)\right) B_{k}(t)-G\left(u_{1, k}(t), B_{k}(t)\right)-C\left(u_{2, k}(t), B_{k}(t)\right)$

where $A\left(t, B_{k}\right)$ is the transition matrix related to the natural dynamics of the grassland relying on growth, decay, and senescence processes. It depends on time $t$ and grass biomass at time $t B_{k}(t)$. $C$ is the mowing function, which depends on $B_{k}(t)$ and $u_{2, k}(t)$ : the mowing intensity $\left(u_{2, k}=0\right.$ or 1$)$. When mowing occurs, $u_{2, k}(t)=1$, all biomass above $5 \mathrm{~cm}$ is harvested. $G\left(u_{1, k}(t), B_{k}(t)\right)$ is the grazing function, which depends on $B_{k}(t)$, and $u_{1, k}(t)$ : the cattle density in field $k$ at time $t$. For further details on the grassland dynamics, see Sabatier et al. (2010).

\subsection{Dynamics of the Lapwing population}

The Lapwing-dynamic model is a female-centered, stage-structured matrix model (Caswell, 1989) commonly used when modeling wader population dynamics (Klok et al., 2009; Hitchcock and Gratto-Trevor, 1997). It is based on two age classes: the first class consists of juveniles $N_{j u v, k}$, and the second class consists of adults $N_{a d, k}$ in field $k$. The choice of a deterministic matrix model for 
Lapwing dynamics has two main advantages. First it maintains a methodological coherence with the matrix-based biomass model, and second, it has the advantage of parsimony compared with models including environmental stochasticity (Tichit et al., 2007).
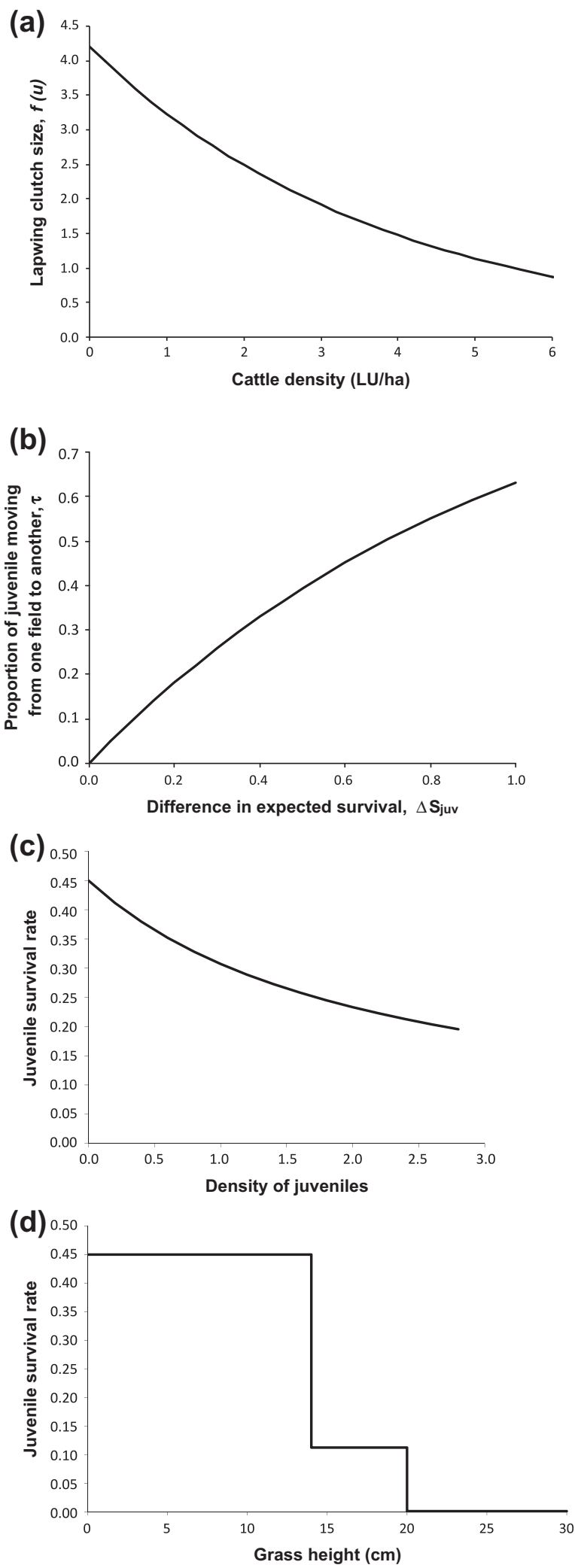

Lapwings are considered juveniles for the first month after hatching. For simplicity, we put all individuals that were more than 1 month old into a category that we labeled "adult". Lapwing dynamics are linked to biomass dynamics and to grassland management. Four key events define the dynamics of the birds: adult distribution, nesting, juvenile re-distribution, and adult survival (Fig. 2).

\subsubsection{Adult distribution}

At the beginning of the year (March; $t=3$ ), the adult Lapwings in all fields are redistributed evenly across the $K$ fields composing the landscape.

$\operatorname{March}(t=3) \quad\left\{\begin{array}{l}N_{j u v, k}(t+1)=0 \\ N_{a d, k}(t+1)=\frac{1}{K} \sum_{k=1}^{K} N_{a d, k}(t)\end{array}\right.$

In the first year, it is the initial population $N_{a d, t o t}$, which is distributed evenly.

\subsubsection{Nesting}

In April $(t=4)$, nest trampling by cattle can destroy eggs and decrease fecundity. During this period, fecundity $F$ (the number of juveniles per adult) is a function of the cattle density $u_{1, k}(t)$.

April $(t=4) \quad\left\{\begin{array}{l}N_{j u v, k}(t+1)=F\left(u_{1, k}\right) \cdot N_{a d, k}(t) \\ N_{a d, k}(t+1)=N_{a d, k}(t)\end{array}\right.$

where $F\left(u_{1, k}\right): F\left(u_{1, k}\right)=\alpha \cdot \sigma \cdot f\left(u_{1, k}\right)$; with $\alpha$ being the proportion of females that are of reproductive age, $\sigma$ the sex ratio, and $f\left(u_{1, k}\right)$ the clutch size, which depends on the cattle density $u_{1, k}$ during the nesting period (Fig. 3a) through the relationship

$f\left(u_{1, k}\right)=f_{\max } \eta^{\eta^{*} u_{1, k}}$

where $f^{\max }$ is the maximum fecundity without trampling, $\eta$ the daily survival rate of eggs, and $t^{*}$ the length of the incubation period of the eggs.

\subsubsection{Juvenile re-distribution and survival}

In May $(t=5)$, two successive events occur: juvenile re-distribution and juvenile survival.

$$
\text { May }(t=5) \quad\left\{\begin{array}{l}
N_{j u v, k}(t+1)=0 \\
N_{a d, k}(t+1)=N_{a d, k}(t)+S\left(D\left(k, N_{j u v, \bullet}(t), B_{\bullet}(t)\right), B_{k}(t)\right)
\end{array}\right.
$$

where $D$ is the juvenile-migration function, and $S$ is the juvenilesurvival function. $N_{j u v, \bullet}$ and $B_{\bullet}$ are the population sizes and the biomass in all fields and are read as follows: $N_{j u v, \bullet}=\left\{N_{j u v, k} \mid k \in L\right\}$ and $B_{.}=\left\{B_{k} \mid k \in L\right\}$, where $L$ is the set of fields in the landscape.

The re-distribution function $D$ calculates the number of juveniles present in field $k$ after re-distribution. The function $D\left(k, N_{j u v, \bullet}, B_{\bullet}\right)$ reflects immigration and emigration mechanisms:

$D\left(k, N_{j u v, \bullet}, B_{\bullet}\right)=N_{j u v, k}+\sum_{i \in V_{8}(k)} \tau_{i k}\left(B_{\bullet}\right) N_{j u v . i}-\sum_{i \in V_{8}(k)} \tau_{k i}\left(B_{\bullet}\right) N_{j u v, k}$

where $\quad \sum_{i \in V_{8}(k)} \tau_{i k}\left(B_{\bullet}\right) N_{j u v, i}$ stands for immigration, and $\sum_{i \in V_{8}(k)} \tau_{k i}\left(B_{\bullet}\right) N_{j u v, k}$ stands for emigration. $V_{8}(k)$ is the set of eight fields adjacent to field $k$. The migration function $\tau_{m n}\left(B_{\bullet}\right)$, with

Fig. 3. Functions of Lapwing clutch size (a), juvenile migration (b), and juvenile survival (c and d). The Lapwing clutch size (Eq. (4)) is presented as a function of cattle density during the nesting month (a), and juvenile migration (Eq. (7)) is presented as a function of the difference in juvenile survival between two adjacent fields (b). Juvenile survival (Eq. (8)) is presented as a function of juvenile density with no grass-height effect (c) and as a function of grass height without density dependence $(\mathrm{d})$. 
$(m, n) \in\{(i, k),(k, i)\}$, stands for the proportion of juveniles moving from field $m$ to field $n$. This function reflects the juveniles' preference for fields that offer better habitat quality (i.e., short grass heights). This migration function depends on $\Delta s_{j u v}\left(h\left(B_{\bullet}\right)\right)$ : the difference in expected juvenile survival between the field of birth and the adjacent fields. Habitat-selection mechanisms constitute a wide study area in landscape ecology (Kristan, 2003; Pulliam and Danielson, 1991), but the data needed to draw the shapes of habitat-selection functions are very difficult to obtain. In the absence of precise knowledge of a habitat-selection function in the case of the Lapwing, we adapted the negative exponential function used by Akcakaya et al. (2004) replacing the distance by the quality of the habitat and normalizing it to ensure a constant population. This migration function is a concave function that is coherent with the nidifugous behavior of the juveniles. The concave shape means that high levels of dispersal are expected even with small differences in habitat quality. The shape of the curve is given by Fig. $3 \mathrm{~b}$.

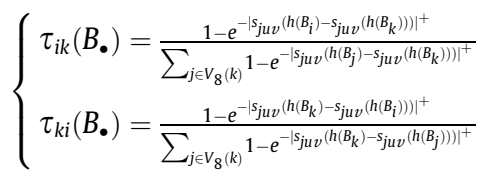

With $|X|^{+}=\max (0, X)$, the juvenile-survival function $S_{k}$ reads as follows:

$S_{k}\left(N_{j u v, k}, B_{k}\right)=\frac{S_{j u v}\left(h\left(B_{k}\right)\right) N_{j u v, k}}{1+c N_{j u v, k}}$

where $s_{j u v}\left(h\left(B_{k}(t)\right)\right)$ is the impact of the grass height of field $k$ on survival. Juvenile survival is also impacted by intra-specific competition represented by a Beverton-Holt-type density-dependence function, where $c$ represents the strength of the competition (Fig. 3c and d).

\subsubsection{Adult survival}

For adults that are able to fly, we applied a constant adult-survival coefficient reflecting independence from the local management regime. For the sake of simplicity, it was considered that annual adult survival $\left(s_{a d}\right)$ occurs in December $(t=12)$ :

December $(t=12) \quad\left\{\begin{array}{l}N_{j u v, k}(t+1)=0 \\ N_{a d, k}(t+1)=s_{a d} \cdot N_{a d, k}(t)\end{array}\right.$

For all other months, $N_{a d, k}(t+1)=N_{a d, k}(t)$ and $N_{j u v, k}(t+1)=N_{j u v, k}(t)$.

\subsection{Model calibration}

\subsubsection{Grazed-grass sub-model}

Three databases from the study area (Marais Poitevin marsh) were used to parameterize the grazed-grass dynamics. The relationship between grass height $(h)$ and grass biomass $(B)$ was modeled by a linear regression with no intercept ( $\mathrm{lm}$ procedure, $\mathrm{R}$ software) based on data from a harvesting trial conducted on 15 grazed fields in 2004 to derive the relationship between grass height and biomass. The parameters of the natural dynamics of the grass were calibrated using grass-height measurements from 74 un-grazed fields (Durant et al., 2008a). The calibration was done by minimizing the mean-square error (MSE) between the predicted and measured grass heights. Once the natural dynamics were calibrated, the grazing parameter $q$ was calibrated using a backward-calibration method on a third dataset containing sequences in grazing intensities and grass heights recorded from 12 fields in 2002 (Tichit et al., 2005). Calibration was also performed by minimizing the MSE. After this last step, an MSE of $27 \mathrm{~cm}^{2}$ was obtained which corresponds to a $5.2 \mathrm{~cm}$ root-meansquare error.

\subsubsection{Lapwing sub-model}

Most Lapwing demographic parameters were based on data from the literature. Reviews on Lapwing demography emphasize low reproductive success (mean clutch size around four eggs, high nest failure, and one brood per year) and relatively high adult survival (around 0.7) (Sandercock, 2003). Due to the lack of precise data for the relationship between chick survival and grass height, a threshold approach was used (Tichit et al., 2007). The effect of nest trampling on the fecundity of the Lapwing was calibrated from Beintema and Muskens (1987) who quantified the effect of one livestock unit on the daily survival rate of eggs. The initial Lapwing population $\left(N_{j u v}(0)=0, N_{a d}(0)=41\right)$ was set to the population densities observed in the study area (Durant et al., 2008a). The coefficient of competition was based on the relationship linking the number of broods to the grass height established by Galbraith (1988).

For full details on the parameter values and calibrations of both the grass and the Lapwing sub-models, see Sabatier et al., 2010.

\subsection{Simulations}

We simulated different types of landscapes based on three management regimes (Fig. $4 \mathrm{a}-\mathrm{c}$ ): productive grazing (PG), ecological grazing (EG), and spring mowing combined with light autumn grazing (M). This functional typology of management regimes was derived from Sabatier et al. (2010), where management regimes were identified based on differences in their impacts on the key stages of the Lapwing life cycle (Table 2). Both types of grazing management (PG and EG) generate relatively short grass heights ensuring high juvenile survival rates. Productive grazing is defined by heavy cattle densities during the nesting period and therefore a high level of trampling. It has a strong negative effect on Lapwing fecundity. Ecological grazing corresponds to low levels of cattle density during nesting, and thus a limited trampling risk that maintains fecundity at a relatively high level. Mowing occurs at the end of May, after the nesting period, and does not impact fecundity. However, grass height has grown too high in hay fields to provide suitable habitats, and juvenile survival is low. The combination of spring mowing with light grazing in autumn generates similar grass heights at the beginning of the year in fields with each of the three management regimes (PG, EG, and $M$ ). This makes it possible to avoid effects on the adults' choice of a nesting site.

After a brief descriptive analysis of the different dynamics at the field scale based on four situations focusing on one field and its immediate surroundings, we tested our two hypotheses on fullsize, $8 \times 8$ landscapes by simulating three different scenarios (Table 2):

- Scenario 1. Landscapes with fields managed by mowing (M) and productive grazing $(P G)$.

The management regimes are complementary. Each management regime is suitable for a single stage of the Lapwing life cycle (Table 2). These landscapes enabled us to test Hypothesis 1 (Fig. 1a).

- Scenario 2. Landscapes with fields managed by productive grazing $(P G)$ and ecological grazing (EG).

The management regimes are compensatory with PG implying more trampling (and thus a lower fecundity rate than EG). This pair of management regimes acts as a control for Hypothesis 1 . There is no complementation between the management regimes (Table 2), and we did not expect to see any significant effect of the structure of the landscape on the Lapwing populations.

- Scenario 3. Landscapes with fields managed by three management regimes. 
(a) Productive grazing surrounded by productive grazing
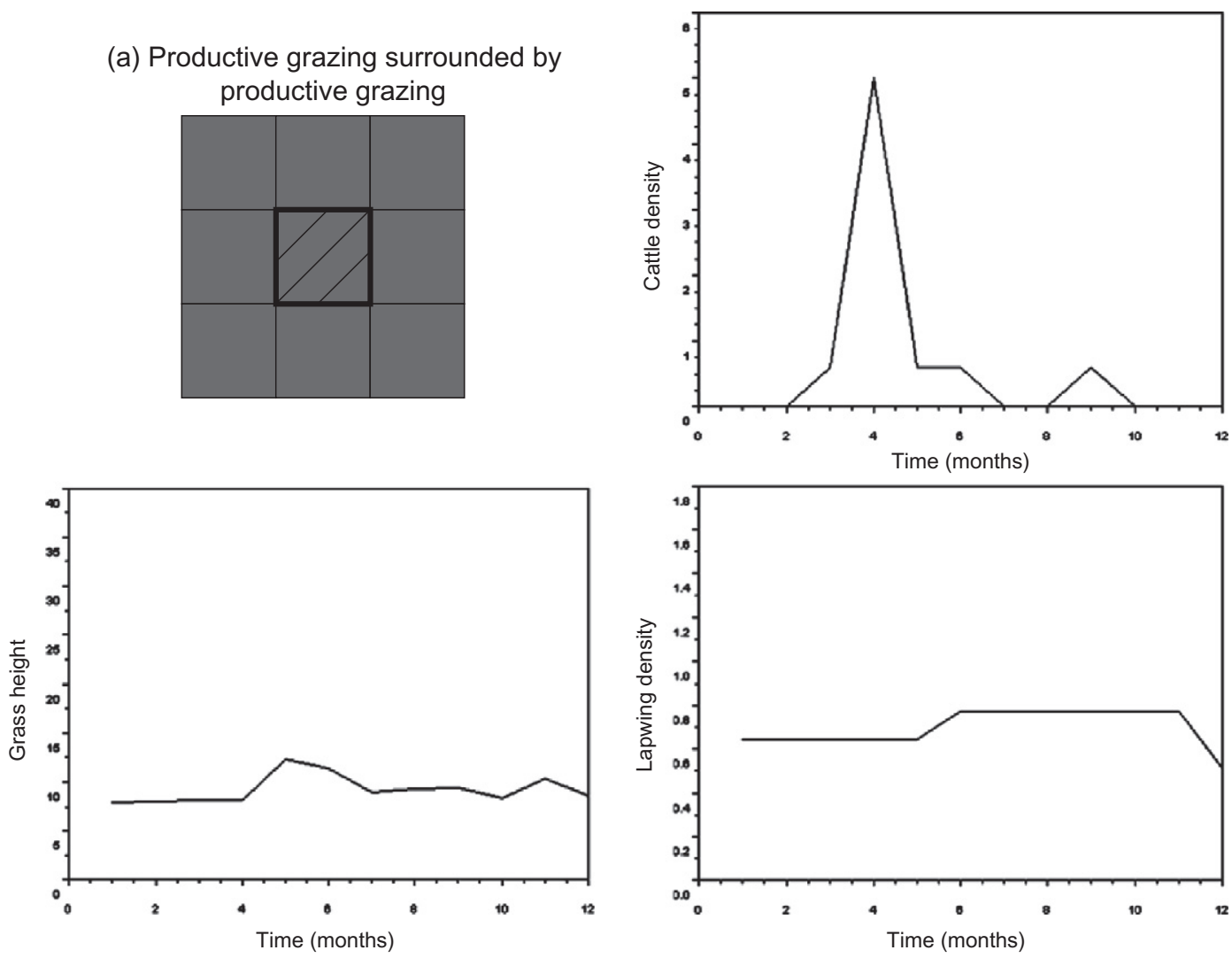

(b) Ecological grazing surrounded by ecological grazing
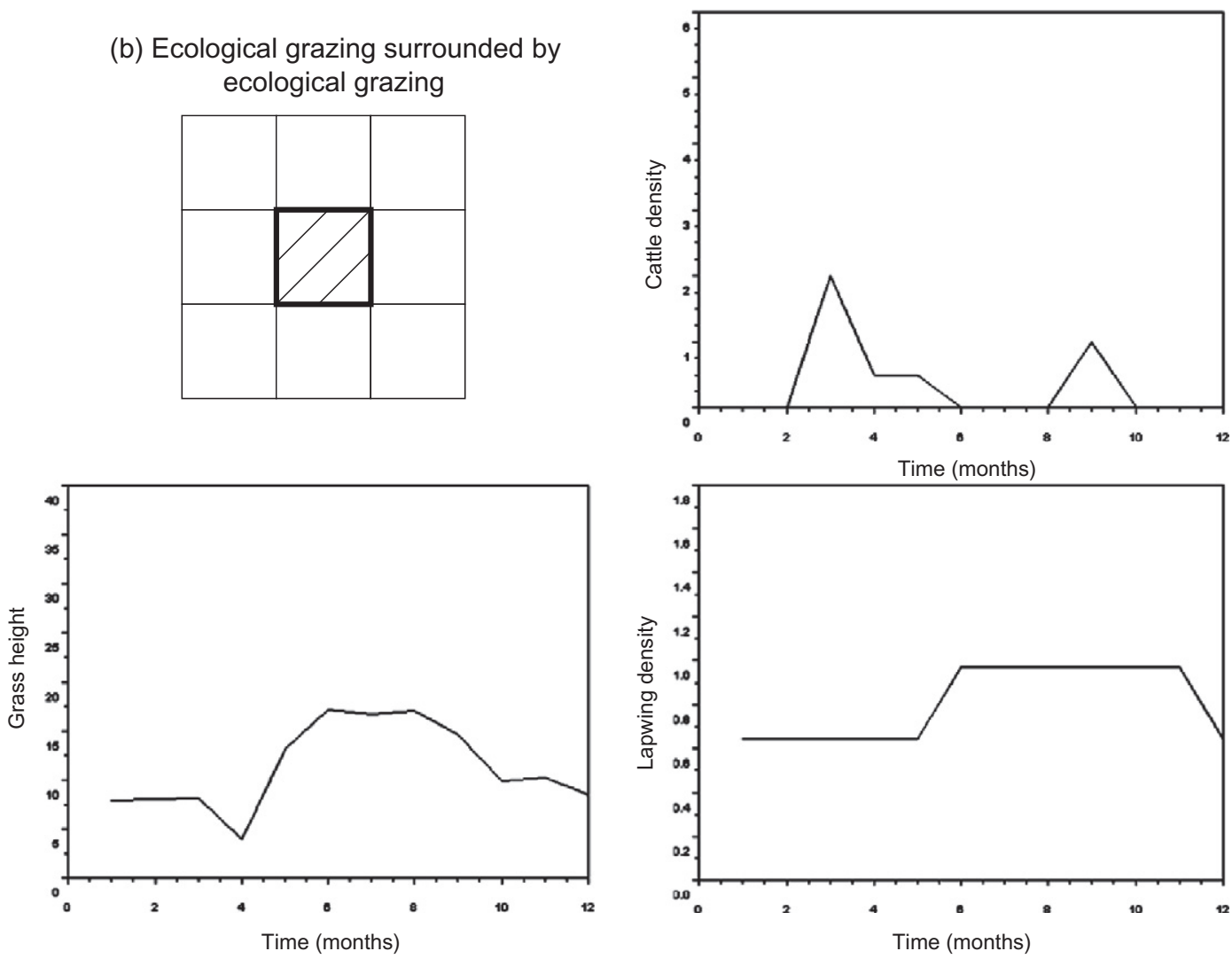

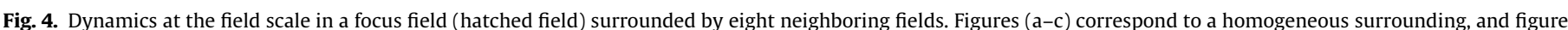

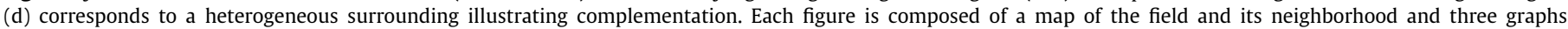

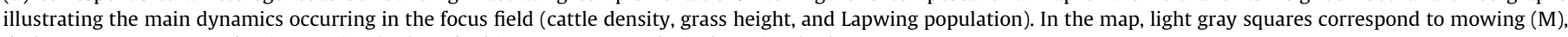
dark gray squares to productive grazing (PG), and white squares to ecological grazing (EG). 
(c) Mowed field surrounded by
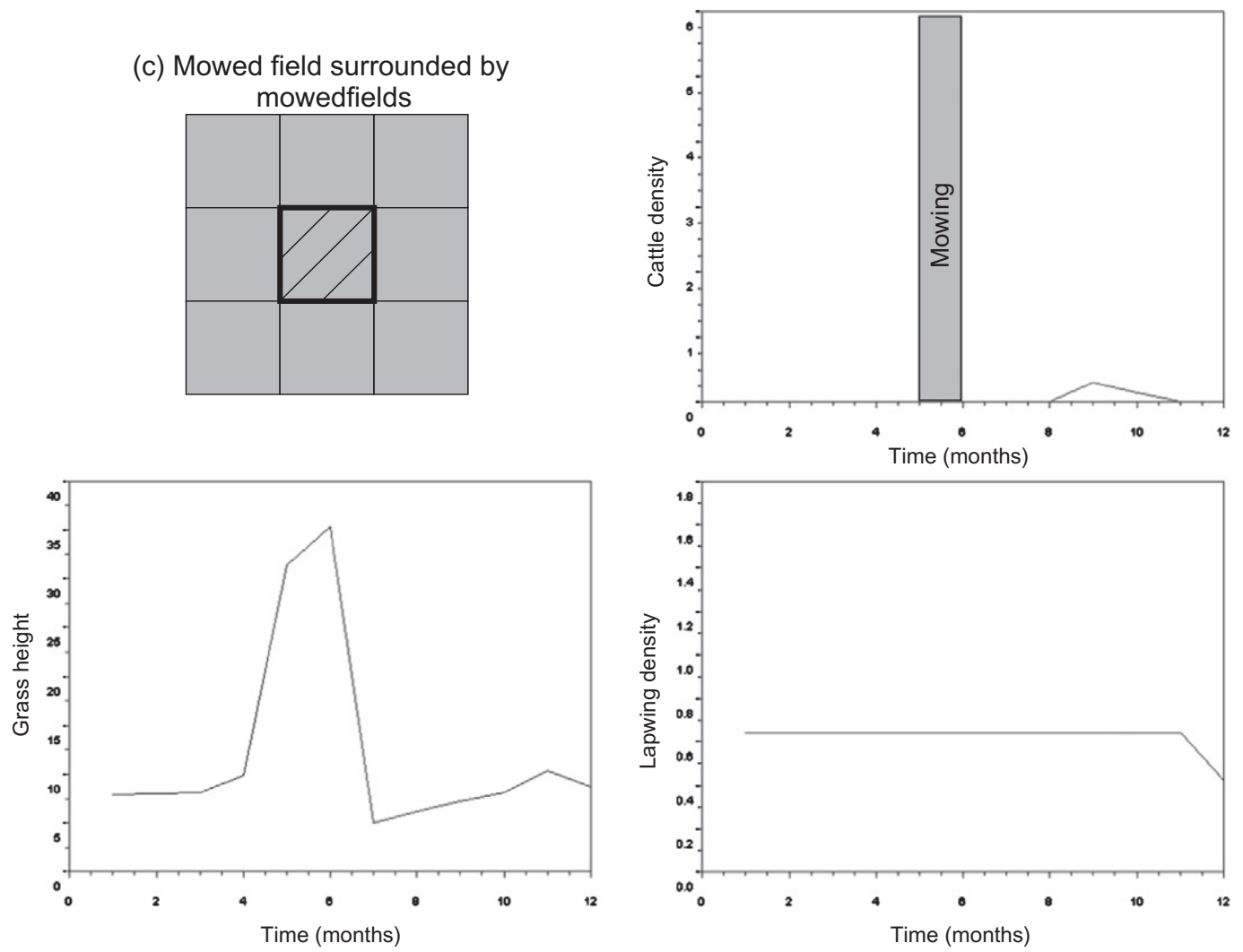

(d) Productive grazing surrounded by mowed fields
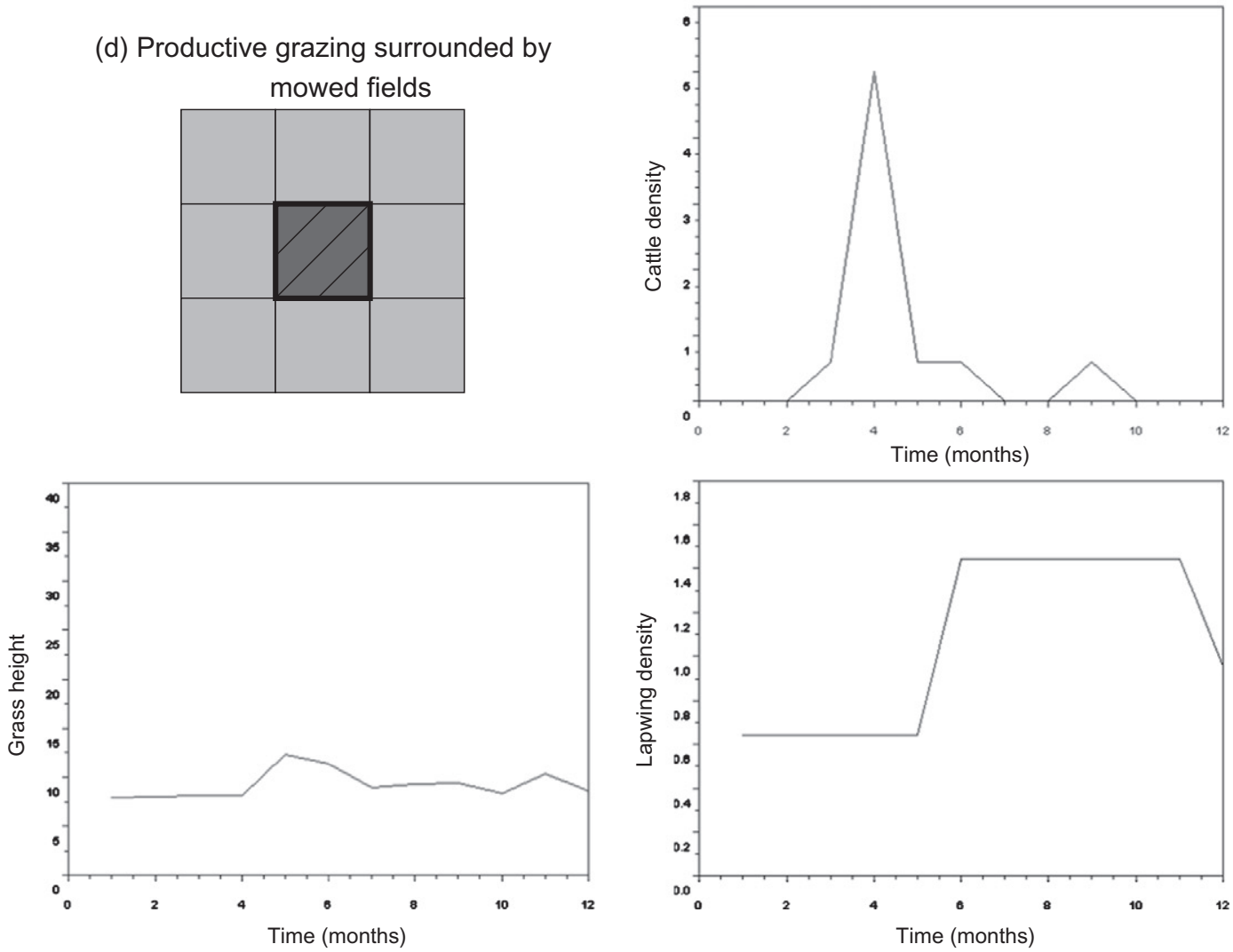

Fig. 4. (continued) 
Table 2

Different management regimes taken into account in the model and their qualitative effects on the demographic parameters of birds (after Sabatier et al., 2010).

\begin{tabular}{|c|c|c|c|}
\hline \multirow[t]{2}{*}{ Landscapes } & \multirow[t]{2}{*}{ Management regimes } & \multicolumn{2}{|c|}{ Impact of management regimes } \\
\hline & & Fecundity $(F)$ & Survival $\left(s_{j u v}\right)$ \\
\hline \multirow[t]{2}{*}{ Scenario 1: Pairs of complementary management regimes } & Mowing & + & - \\
\hline & Productive grazing & - & + \\
\hline \multirow[t]{2}{*}{ Scenario 2: Pairs of compensatory management regimes } & Productive grazing & - & + \\
\hline & Ecological grazing & + & + \\
\hline \multirow[t]{3}{*}{ Scenario 3: All management regimes } & Productive grazing & - & + \\
\hline & Ecological grazing & + & + \\
\hline & Mowing & + & - \\
\hline
\end{tabular}

These landscapes, corresponding to a mixture of compensation and complementation mechanisms, enabled us to test Hypothesis 2 (Fig. 1b). Mowing is constant and covers the same proportion as in our case study (39\% of the landscape).

The first algorithm simulated landscapes with a uniform distribution of management regimes. Management was assigned randomly to fields. Simulated landscapes thus had a low aggregation of management regimes.

To generate variable levels of land-use clustering, and thus variable levels of complexity in the landscape structure, we used Neyman-Scott processes. A Neyman-Scott process is a point process built from a homogeneous Poisson process defining a set of "father" points that serve as centers for clusters of "son" points. Each cluster of son points is obtained by a non-homogeneous Poisson process centered on the father point upon which the cluster depends. For more details on Neyman-Scott processes, see Ripley (1977). The simulated landscapes were obtained using the R software: rNeymanScott function of the Spatstat package (Baddeley and Turner, 2005). This algorithm made it possible to generate landscapes with different levels of land-use clustering. A wide set of parameter values were used in the rNeymanScott function, and a large number of replications were computed. Thus, we simulated more Neyman-Scottbased landscapes than uniform landscapes.

For each of the first two scenarios, we simulated 38,100 landscapes, of which 37,000 were generated by the Neyman-Scott process and the other 1100 by algorithms based on uniform distributions. For Scenario 3, we simulated 117,000 landscapes, of which 111,000 were generated by Neyman-Scott processes and the other 6000 by algorithms based on uniform laws. From this set of landscapes, we extracted a sub-set $(n=22,356)$ of landscapes having a constant proportion of mowing identical to that observed on the study site (39\%; Sabatier et al., 2008).

Each simulated landscape was characterized by two indices: the proportion of different management regimes ( $p(P G), p(E G), p(M)$ ), and an index of landscape structure $I_{S}$ representing the total number of interfaces between fields with different management regimes (Queen's adjacency):

$I_{S}=\frac{1}{2} \sum_{k \in L} \sum_{i \in V_{8}(k)} 1_{\left\{u_{k} \neq u_{i}\right\}}$

where $u=\left[\begin{array}{l}u_{1} \\ u_{2}\end{array}\right], 1_{\left\{u_{k} \neq u_{i}\right\}}$ is the characteristic function related to the event $\left\{u_{k} \neq u_{i}\right\}$ that takes the value 1 if $u_{k} \neq u_{i}$ and 0 if $u_{k}=u_{i}$.

For each landscape, the model calculates an ecological performance indicator, which is equal to the adult Lapwing population at time horizon $N_{a d}(T)$. In the landscape composed of three land uses, the agricultural performance is obtained with a grazed-grassland production index $P$ that corresponds to the number of days for which cattle feed is provided by grasslands. The higher this index is, the greater the forage production of the landscape will be. It is expressed in livestock units days per ha grazed pastures (LU days/ha):
$P=1 / S_{L^{\prime}} \sum_{k \in L^{\prime}} \sum_{t=1}^{12} 30 u_{1, k}(t)$

where $L^{\prime}$ is the subset of grazed fields in the landscape, and $S_{L}$, is the surface area of the landscape. The proportion of mowed pasture being kept constant, this index only focuses on the grazed biomass. A property of this index is that it is a linear function of $p(E G)$ since it can also be written as follows:

$P=\operatorname{Perf}_{P G}+p(E G)\left(\operatorname{Perf}_{E G}-\operatorname{Perf}_{P G}\right)$

with $\operatorname{Perf}_{P G}$ and $\operatorname{Perf}_{\mathrm{EG}}$ the number of days for which cattle feed is provided by grasslands in land uses PG and EG.

\section{Results}

\subsection{Dynamics at the field scale}

The first three series of field-scale dynamics illustrate the different dynamics in a homogeneous spatial context.

Fields managed with productive grazing (Fig. 4a) were characterized by a high cattle density in April leading to suitable grass height in May. This led to both low fecundity and high juvenile survival. Therefore, juveniles becoming adults promoted a slight increase in the adult population in the summer. However, this was not sufficient to compensate for the adult mortality occurring in winter, and the overall effect of this management regime was a decrease in the Lapwing population.

In fields managed with ecological grazing (Fig. 4b), grazing intensity in April was constrained to ensure suitable grass heights with limited nest trampling. Therefore, fecundity was moderate, while survival was high. This led to an increase in the adult population in summer that was sufficient to maintain the adult population over the year.

Mowed fields (Fig. 4c) were not grazed in April, and grass height was thus very high in May. Fecundity was thus at its maximum, but juvenile survival was very low. Almost no juveniles became adults, which led to an overall decrease in the Lapwing population.

The fourth series of field-scale dynamics (Fig. 4d) illustrates the mechanism of complementation. Even if the field managed with productive grazing led to low fecundity, it benefited from the high fecundity in the surrounding mowed fields. Juveniles born in the surrounding fields migrated to the attractive productive pasture (with short grass height), and thus a high number of juveniles became adults. Overall, we observed an important increase in the Lapwing population.

\subsection{Dynamics at the landscape scale}

\subsubsection{Landscapes with two complementary management regimes (Scenario 1)}

Fig. 4 shows the Lapwing population size in a large number of landscapes with different structures and land-use proportions. Our simulations showed a non-monotonous effect of the propor- 

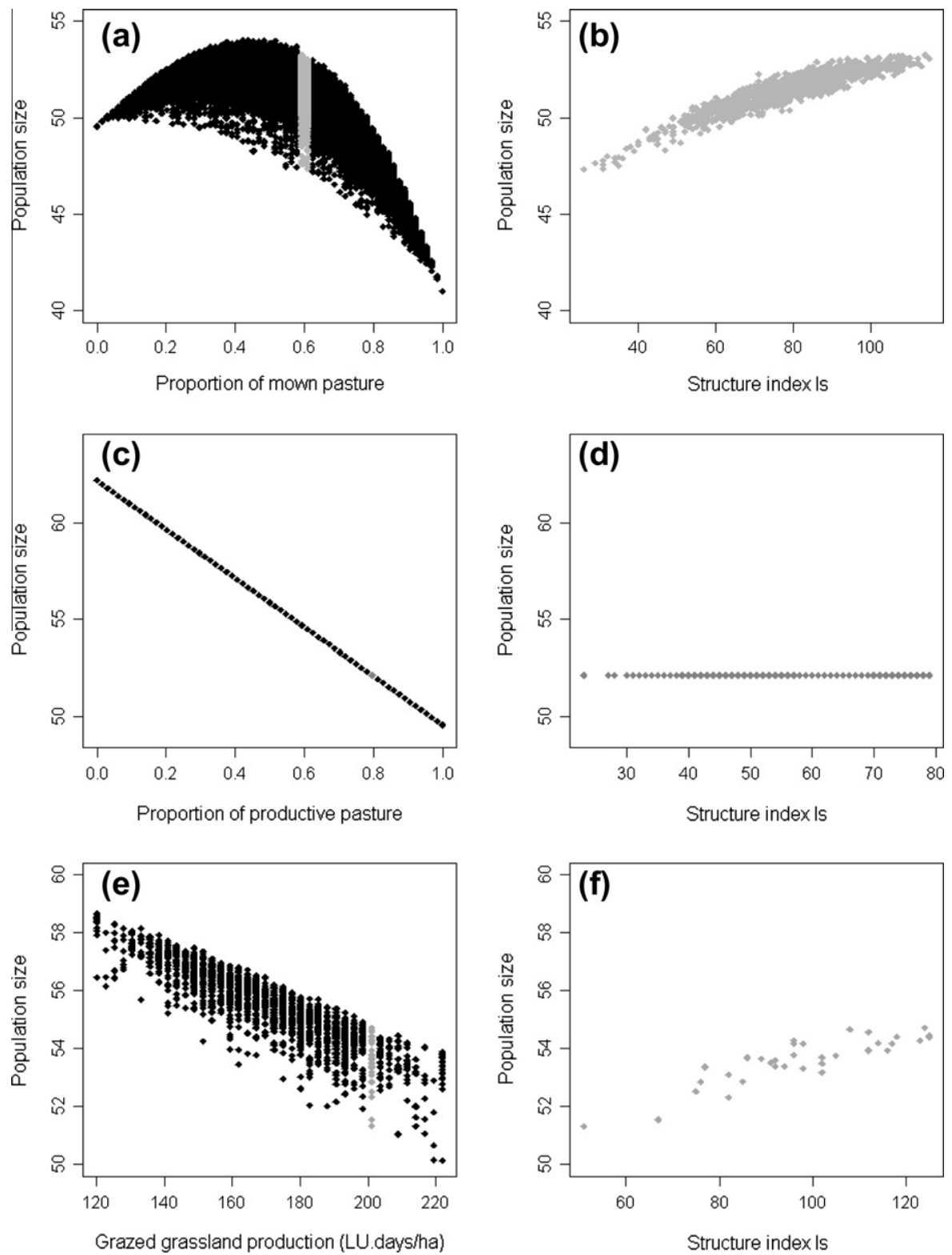

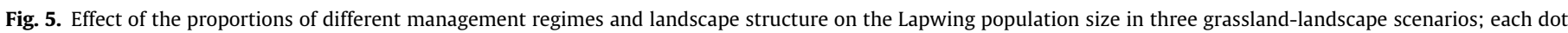
corresponds to a different landscape. Panels (a and b) correspond to landscapes made of two complementary management regimes (Scenario 1), the landscapes in gray are composed of $60 \%( \pm 1 \%)$ mowing $(\mathrm{M})$. Panels ( $\mathrm{c}$ and d) correspond to landscapes made of two compensatory management regimes (Scenario 2 ), the landscapes in gray are composed of $60 \%$ ( $\pm 1 \%$ ) productive grazing (PG). Panels (e and f) represent landscapes with three management regimes (Scenario 3), mowing proportion is set to $39 \%$ ( $\pm 1 \%$ ), the landscapes in gray are composed of $10 \%( \pm 1 \%)$ ecological pasture (EG). The grazed-grassland production index (expressed in livestock units days/ha) represents agricultural performance and is a linear function of the PG/EG ratio. The structure index corresponds to the total number of interfaces between fields with different management regimes (including the corners).

tion of mowing on Lapwing population sizes (Fig. 5a). The best population sizes were obtained with intermediate mowing proportions, fitting the humped shape of the theoretical graph in Fig. 1a. However, the asymmetric pattern reflected the result that landscapes composed only of productive grazing were better for Lapwings than landscapes with mowing only. For a given mowing proportion (60\% in the example in Fig. 5), we found variation in the range of population sizes, especially for the intermediate mowing proportions. These landscapes were then plotted according to their structure (Fig. 5b). The variability in population sizes that could not be explained by the proportions of management regimes was then clearly explained by the landscape structure (linear regression, $p<0.001, R^{2}=0.84$ ). High levels of structure indices, and hence high complexity in the spatial arrangements of manage- ment regimes, favored the Lapwing populations. This result illustrates the importance of interfaces between the different management regimes offering complementary habitats for Lapwings, and therefore confirms the hypothesis associated with the first pair of management regimes; where over and above the proportions of different management regimes, the landscape structure was an important determinant of Lapwing populations in landscapes composed of complementary habitats.

\subsubsection{Landscapes with two compensatory management regimes (Scenario 2)}

Fig. 5c shows Lapwing population sizes in a large number of landscapes with different structures and proportions of management regimes. There was a negative linear relationship between 
the proportion of productive grazing and the population size (linear model, $\left.p<0.001, R^{2}=1\right)$. For a constant proportion of management regimes (60\% of productive grazing in the example in Fig. $5 \mathrm{c}$ and $d$ ), the landscape structure had no effect on the population sizes (Fig. 5d). By illustrating that without complementation between management regimes the landscape structure had no effect on ecological performance, these results support Hypothesis 1.

\subsubsection{Landscapes with three management regimes mixing compensatory and complementary mechanisms (Scenario 3)}

Fig. 5e shows the Lapwing population size in a large number of landscapes with different structures and proportions of management regimes. In these landscapes, a strong trade-off existed between agricultural performance and ecological performance (Fig. 5e). Landscapes with the highest levels of grazed-grassland production had the lowest Lapwing population sizes and vice ver$\mathrm{sa}$, and the correlation between grazed-grassland production and population sizes was strong (linear model, $p<0.001, R^{2}=0.11$ ). As the grazed-grassland production was a linear function of the PG/EG ratio, the PG/EG ratio was logically negatively correlated with ecological performance. There was nevertheless a large part of the variance that was not explained by the proportions of different management regimes. These landscapes where then plotted according to their structure (Fig. 5f). For a constant proportion of ecological grazing (e.g., $10 \pm 1 \%$ in the example in Fig. $5 f$ ), this residual variance was well explained by the landscape structure (linear model, $p<0.001, R^{2}=0.76$ ). For a given landscape composition, and thus a constant level of agricultural performance, an increase in the complexity of the spatial arrangement of the management regimes was a way of improving its ecological performance without losing on the agricultural dimension. This result confirms Hypothesis 2.

\section{Discussion}

The aim of the model was not to give accurate quantitative predictions. The simulated outputs must first be interpreted qualitatively, not as exact predictions, showing trends and recognizable patterns and providing references for testing the hypotheses. Our results confirmed that the proportions of fields managed with different management regimes strongly determined the trade-offs between herbage production and Lapwing population size in the grassland agro-landscapes. Along with the proportions of different management regimes, modifying their spatial arrangement could improve the trade-off between agricultural and ecological performances by facilitating mechanisms of complementation between management regimes.

\subsection{Toward a predictive model}

Even though we tried to reflect the case study as much as possible, several aspects limit its use as a predictive tool, and further work would be needed to improve it in that direction.

By considering the total population size, we used one of the simplest indicators of ecological performance. In the field, such an indicator is often misleading. A high population size does not necessarily mean a healthy population, because many mechanisms; linked, for example, to the social behavior of the considered species, environmental stochasticity, or meta-population dynamics; may impact local population sizes, leading to high local abundance even with a declining population at the regional scale (Van Horne, 1983). However, in our model, which focused on the effects of farming on Lapwing dynamics, these mechanisms were not taken into account, and more complex indicators would not have improved the quality of the outputs. We therefore cannot conclude that high levels of heterogeneity would lead to viable populations; but we can say that, all other things being equal, populations are expected to be larger in landscapes with more structural heterogeneity favoring mechanisms of complementation. To more accurately predict population sizes, our model should integrate significant factors for the Lapwings such as field wetness (Durant et al., 2008a) and larger-scale meta-population dynamics.

In this study, we only considered a few contrasting management regimes. Due to the structure of our model, in particular the state-control modeling of the grassland dynamics and its links to Lapwing population dynamics, it would be feasible to simulate landscapes composed of more complex associations of management regimes and/or a larger number of management regimes. For instance, it would be possible to use the current relative proportions of management regimes in our study area as input data or to simulate management regimes favorable to other bird species. A species such as the Common Redshank (Tringa totanus), commonly nesting in our study area, would be a good candidate. In other European areas, the Black-Tailed Godwit, already targeted by the mosaic-management agri-environment schemes in the Netherlands (Schekkerman et al., 2008), could also be a species of particular interest.

Applying our model to the assessment of other landscapes where the landscape structure is not as simple as that of the Marais Poitevin (high geometric regularity of the landscape shaped by rills and canals) would require some methodological considerations. First, the size and shape of the fields could not be treated in such a simple way. A solution could be to increase the resolution of the landscape and/or to change the shape of the pixels. Second, the heterogeneity index would raise problems if used in its current state. Instead of simply counting the interfaces, an alternative index could be based on the proportions of complementary management regimes within a circle corresponding to the home range of the juvenile.

In this study, we only focused on the levels of heterogeneity favorable to a bird species, but another question is which spatial arrangement can be attained by farming systems. Agro-landscapes consist of several interacting farms; and in each farm, the spatial arrangement of land uses and management regimes stems from the interactions among the farmer's strategic objectives (Coleno and Duru, 1998), the physical constraints of the fields (Morlon and Benoit, 1990), and environmental variations (e.g., market price and climate). Not all landscape structures are realistic from an agronomic point of view, and farm-scale constraints should be integrated in the model to reflect the set of realistic landscapes. In our study area, they mainly reflect the physical constraints of the farm (Havet et al., 2005): the distance from a field to the main building of the farm, field wetness, the presence of rills and canals, etc. Including these constraints in the model would imply the explicit formalization of the farm territories as well as the linear elements of the landscape (canals, rills, and roads) and soil characteristics.

Finally, no validation of the model was conducted. The validation of this type of multi-scale model would require monitoring data on Lapwing survival and fecundity and farming practices on a landscape scale. The spatial unit would have to be the field and the temporal unit 1 month, with a sufficiently long timeline to avoid effects linked to climate variability. It would therefore be costly to obtain such data. A full validation of the model seems quite difficult to obtain. Partial validation of the different modules of the model, based on available data and expert knowledge, would be a more cost-effective option.

\subsection{Managing landscape heterogeneity}

Our results illustrate the importance of the structure of landscapes for reconciling agricultural and ecological performances in 
agro-landscapes. In this respect, they are consistent with recent studies in landscape ecology (Benton et al., 2003; Groot et al., 2010; Haslem and Bennett, 2008). These studies generally highlight the heterogeneity of landscapes as a factor promoting the diversity of available habitats and thus allowing for an increase in species richness. By drawing on the case of complementary habitats, we have shown, additionally, that apart from relations of the "one species = one habitat" type, it was possible to preserve species by means of a set of interacting sub-optimal habitats. Each habitat provides some of the resources needed, and mobility between habitats enables a species to obtain all of the resources that it needs. These mechanisms have often been put forward to explain the role of intra-field heterogeneity in the cases of birds (Durant et al., 2008a; Arlettaz et al., 2009) and arthropods (Dennis et al., 1998). However, at the inter-field level, few studies have examined complementation mechanisms. These mechanisms are mentioned by Benton et al. (2003), who highlight the importance of the proximity of sources of food for nidifugous birds. They were also the main subjects of the work of Brotons et al. (2005), who statistically tested these mechanisms in the case of grassland birds.

As agro-ecosystems have undergone profound change, the habitats that they offer are often only partially favorable to those species that thrive in agro-landscapes. In this context, by favoring mechanisms of complementation, an increase in the complexity of spatial structure could be a way of compensating for partial losses of resources in the various habitats affected by agricultural intensification. The question that then arises concerns the scale on which this heterogeneity should be considered (intra- or inter-field). The relevant scale depends heavily on the species under consideration and its capacity for mobility. However, to date, very few researchers have focused on both intra- and inter-field heterogeneity (although one example is Smith et al., 2004).

Working on larger spatial scales means bringing together several actors to implement wildlife-friendly management. Territorial management schemes, such as the mosaic management in the Netherlands (Schekkerman et al., 2008), are a way of generating levels of heterogeneity in agro-landscapes that are favorable to biodiversity. Today, the coordination tools developed under this measure have paved a promising way for facilitating synergies among farms (Melman et al., 2010). In practice, however, the generalization of such measures raises questions concerning collective management. Several examples of successful collective management have been studied (Hannachi and Coleno, 2012) in situations where farmers have a common interest. However, the question remains as to whether farmers would organize themselves on biodiversity issues where the existence of a common interest is not straightforward. The example of the Corn Crake (Crex crex) management in the lower Angevin valley of France shows that biodiversity issues can federate farmers as soon as they acquire the status of experts (Le Guen and Sigwalt, 1999) and biodiversity becomes a way of labeling agricultural products (Billaudeau and Thareau, 2008; Cavrois, 2009). Institutional innovations such as the Dutch environmental cooperatives (Renting and Van der Ploeg, 2001) could be a good way of revealing common interests related to biodiversity. In such a context, models like ours can be used as catalysts of collective management because they provide tools to construct a shared point of view among the different stakeholders.

\section{Conclusion}

Based on a large number of simulated landscapes, our results show that an increase in the complexity of the structure of agrolandscapes is expected to favor the Lapwing population by enhancing mechanisms of complementation among habitats. Playing on the spatial arrangement of management regimes therefore seems to be an effective means of offsetting trade-offs between production and ecological performances in agro-landscapes. As many obstacles still hinder the introduction of schemes to generate levels of heterogeneity that are favorable to biodiversity, considerable efforts would have to be made to develop tools for coordinating different actors' efforts.

\section{Acknowledgments}

This work was carried out with the financial support of Agence Nationale de la Recherche (ANR), The French National Research Agency under the SYSTERRA programme (Ecosystems and Sustainable Development, Project ANR-08-STRA-007), Coviability models of FARMing and BIRD biodiversity (FARMBIRD).

\section{References}

Akcakaya, H.R., Radeloff, V.C., Mlandenoff, D.J., He, H.S., 2004. Integrating landscape and metapopulation modeling approaches: viability of the sharp-tailed grouse in a dynamic landscape. Conserv. Biol. 18, 526-537.

Albrecht, M., Duelli, P., Muller, C., Kleijn, D., Schmid, B., 2007. The Swiss agrienvironment scheme enhances pollinator diversity and plant reproductive success in nearby intensively managed farmland. J. Appl. Ecol. 44, 813-822.

Andren, H., Delin, A., Seiler, A., 1997. Population response to landscape changes depends on specialization to different landscape elements. Oikos 80, 193-196.

Arlettaz, R., Loset, A., Maurer, M., Menz, M., Reichlin, T., Weisshaupt, N., Abadi, F., Schaub, M., 2009. Bare Soil as a Staple Commodity for Declining GroundForaging Insectivorous Farmland Birds. Lowland Farmland Birds III: Delivering Solutions in an Uncertain World, Leicester, UK. <http://www.bou.org.uk/ bouproc-net/lfb3/arlettaz-etal.pdf>.

Baddeley, A., Turner, R., 2005. Spatstat: an R package for analyzing spatial point patterns. J. Stat. Softw. 12, 1-42.

Beintema, A.J., Muskens, G.J.D.M., 1987. Nesting success of birds breeding in Dutch agricultural grassland. J. Appl. Ecol. 24, 743-758.

Benton, T.G., Vickery, J.A., Wilson, J.D., 2003. Farmland biodiversity: is habitat heterogeneity the key? Trends Ecol. Evol. 18, 182-188.

Billaudeau, V., Thareau, B., 2008. "L'éleveur et l'Oiseau": territoires de communication. Colloque Economie sociale et solidaire: Nouvelles pratiques et dynamiques territoriales. Nantes, p. 27.

Brotons, L., Wolff, A., Paulus, G., Martin, J.L., 2005. Effect of adjacent agricultural habitat on the distribution of passerines in natural grasslands. Biol. Conserv. $124,407-414$

Burel, F., Baudry, J., 1999. Ecologie du paysage: concepts, méthodes et applications. Tec \& Doc, Paris, p. 358

Caswell, H., 1989. Matrix Population Models, Sunderland, MA, USA, p. 722.

Cavrois, A., 2009. Biodiversite et signes de reconnaissances agricole. Comite francais de l'UICN, Paris, p. 173.

Coleno, F.C., Duru, M., 1998. Gestion de production en systèmes d'élevage utilisateurs d'herbe: une approche par atelier. Etudes et recherches sur les systèmes agraires et le développement 31, 45-61.

Dennis, P., Young, M.R., Gordon, I.J., 1998. Distribution and abundance of small insects and arachnids in relation to structural heterogeneity of grazed, indigenous grasslands. Ecol. Entomol. 23, 253-264.

Donald, P.F., Sanderson, F.J., Burfield, I.J., van Bommel, F.P.J., 2006. Further evidence of continent-wide impacts of agricultural intensification on European farmland birds, 1990-2000. Agric. Ecosyst. Environ. 116, 189-196.

Dunning, J.B., Danielson, B.J., Pulliam, H.R., 1992. Ecological processes that affect populations in complex landscapes. Oikos 65, 169-175.

Durant, D., Tichit, M., Fritz, H., Kerneis, E., 2008a. Field occupancy by breeding lapwings Vanellus vanellus and redshanks Tringa totanus in agricultural wet grasslands. Agric. Ecosyst. Environ. 128, 146-150.

Durant, D., Tichit, M., Kerneis, E., Fritz, H., 2008b. Management of agricultural wet grasslands for breeding waders: integrating ecological and livestock system perspectives - a review. Biodivers. Conserv. 17, 2275-2295.

Fahrig, L., Baudry, J., Brotons, L., Burel, F.G., Crist, T.O., Fuller, R.J., Sirami, C., Siriwardena, G.M., Martin, J.L., 2011. Functional landscape heterogeneity and animal biodiversity in agricultural landscapes. Ecol. Lett. 14, 101-112.

Galbraith, H., 1988. Effects of agriculture on the breeding ecology of lapwings Vanellus vanellus. J. Appl. Ecol., 487-503.

Green, R.E., Cornell, S.J., Scharlemann, J.P.W., Balmford, A., 2005. Farming and the fate of wild nature. Science 307, 550-555.

Groot, J.C.J., Jellema, A., Rossing, W.A.H., 2010. Designing a hedgerow network in a multifunctional agricultural landscape: balancing trade-offs among ecological quality, landscape character and implementation costs. Eur. J. Agron. 32, 112119.

Hannachi, M., Coleno, F.C., 2012. How to adequately balance between competition and cooperation? A typology of horizontal coopetition. Int.. J. Entrep. Small Bus. 17 (3), 273-289.

Haslem, A., Bennett, A.F., 2008. Birds in agricultural mosaics: the influence of landscape pattern and countryside heterogeneity. Ecol. Appl. 18, 185-196. 
Havet, A., Pons, Y., Kerneis, E., 2005. Evaluer les contraintes spatiales à l'utilisation des prairies et les marges de manoeuvre des exploitations face à des demandes environmentales. Un exemple d'OLAE en Vendée. Les cahiers de la multifonctionnalité 5, 43-55.

Hitchcock, C.L., Gratto-Trevor, C., 1997. Diagnosing a shorebird local population decline with a stage-structured matrix population model. Ecology 78 (2), 522534

Hutchings, N.J., Gordon, I.J., 2001. A dynamic model of herbivore-plant interactions on grasslands. Ecol. Modell. 136, 209-222.

Isaksson, D., 2009. Predation and Shorebirds: Predation Management, Habitat Effects and Public Opinions. Department of Zoology, Gothenburg, p. 45.

Johansson, O.C., Blomqvist, D., 1996. Habitat selection and diet of lapwing Vanellus vanellus chicks on coastal farmland in SW Sweden. J. Appl. Ecol. 33, 1030-1040.

Jouven, M., Baumont, R., 2008. Simulating grassland utilization in beef suckler systems to investigate the trade-offs between production and floristic diversity. Agric. Syst. 96, 260-272.

Julliard, R., Jiguet, F., Couvet, D., 2003. Common birds facing global changes: what makes a species at risk? Glob. Change Biol. 10, 148-154.

Klok, C., Roodbergen, M., Hemerik, L., 2009. Diagnosing declining grassland wader populations using simple matrix models. Anim. Biol., 127-144.

Kristan III, W.B., 2003. The role of habitat selection behavior in population dynamics: source-sink systems and ecological traps. Oikos 103, 457-468.

Kruk, M., Noordervliet, M.A.W., terKeurs, W.J., 1997. Survival of black-tailed godwit chicks Limosa limosa in intensively exploited grassland areas in The Netherlands. Biol. Conserv. 80, 127-133.

Le Guen, R., Sigwalt, A., 1999. Le métier d'éleveur face à une politique de conservation de la bio-diversité. Econ. Rurale 249, 41-48.

Melman, D., Schotman, A., Vanmeulebrouk, B., Kiers, M., Meewsen, H., Roosenschoon, O., De Snoo, G., 2010. An Internet-Accessible Tool for Drawing up Tailor Made Management Plans for Meadow Birds. Aspects of Applied Biology, Agri-Environment Schemes - What Have They Achieved and Where do We Go from Here? Leicester, pp. 405-414.

Morlon, P., Benoit, M., 1990. Methodological study of a farm field pattern as a system. Agronomie 10, 499-508.

Pulliam, H.R., Danielson, B.J., 1991. Sources, sinks, and habitat selection: a landscape perspective on population dynamics. Am. Nat., 50-66.

Redfern, C.P.F., 1982. Lapwing nest sites and chick mobility in relation to habitat. Bird Study 29, 201-208.

Renting, H., Van der Ploeg, J.D., 2001. Reconnecting nature, farming and society: environmental cooperatives in the Netherlands as institutionnal arrangements for creating coherence. J. Environ. Policy Plann. 3, 85-101.
Ripley, B.D., 1977. Modeling spatial patterns. J. Roy. Stat. Soc. Ser. B - Methodol. 39, $172-212$.

Sabatier, R., 2010. Multiscale Trade-Offs Between Agricultural Production and Biodiversity in a Grassland Agroecosystem. Agroparistech, Paris, p. 226.

Sabatier, R., Doyen, L., Tichit, M., 2010. Modelling trade-offs between livestock grazing and wader conservation in a grassland agroecosystem. Ecol. Modell. 221, 1292-1300.

Sabatier, R., Kerneis, E., Tichit, M., 2008. Ecological Evaluation of Landscapes Shaped by Productive Objectives. IFSA International Farming Sysytem Association, Clermont-Ferrand.

Sandercock, B.K., 2003. Estimation of survival rates for wader populations: a review of mark-recapture methods. Wader Study Group, Bull., 163-174.

Schekkerman, H., Teunissen, W., Oosterveld, E., 2008. The effect of "mosaic management" on the demography of black-tailed godwit Limosa limosa on farmland. J. Appl. Ecol. 45, 1067-1075.

Smith, R.K., Jennings, N.V., Robinson, A., Harris, S., 2004. Conservation of European hares Lepus europaeus in Britain: is increasing habitat heterogeneity in farmland the answer? J. Appl. Ecol. 41, 1092-1102.

Sparrow, A.D., 1999. A heterogeneity of heterogeneities. Trends Ecol. Evol. 14, 422 423.

Tichit, M., Renault, O., Potter, T., 2005. Grazing regime as a tool to assess positive side effects of livestock farming systems on wading birds. Anim. Prod. Sci. 96 109-117.

Tichit, M., Doyen, L., Lemel, J.Y., Renault, O., Durant, D., 2007. A co-viability model of grazing and bird community management in farmland. Ecol. Model. 206, 277293.

Tichit, M., Puillet, L., Sabatier, R., Teillard, F., 2011. Multicriteria performance and sustainability in livestock farming systems: functional diversity matters. Livest. Sci. 139, 161-171.

Tscharntke, T., Klein, A.M., Kruess, A., Steffan-Dewenter, I., Thies, C., 2005 Landscape perspectives on agricultural intensification and biodiversity ecosystem service management. Ecol. Lett. 8, 857-874.

Van Horne, B., 1983. Density as a misleading indicator of habitat quality. J. Wild Manag. 47 (4), 893-901.

Vickery, J.A., Tallowin, J.R., Feber, R.E., Asteraki, E.J., Atkinson, P.W., Fuller, R.J., Brown, V.K., 2001. The management of lowland neutral grasslands in Britain: effects of agricultural practices on birds and their food resources. J. Appl. Ecol. 38, 647-664.

Whittingham, M.J., Percival, S.M., Brown, A.F., 2000. Time budgets and foraging of breeding golden plover Pluvialis apricaria. J. Appl. Ecol. 37, 632-646. 